\title{
HACIA UNA TIPOLOGÍA DE LOS VERBOS PRONOMINALES. FRASEOLOGÍA EN LA MUESTRA LEXICOGRÁFICA DE R. J. CUERVO Y V. G. MANRIQUE
}

CATy PALOMARes ExPÓSITO

I.E.S. Santa Engracia, Linares

José PALOMARES EXPÓSITO I.E.S. Huarte de San Juan, Linares

El propósito de este artículo es presentar una tipología incluyente de los verbos pronominales y reflexionar sobre el tratamiento dado al discurso repetido en la Muestra de un diccionario de la lengua castellana (1871).

\section{VERBOS PRONOMINALES EN GRADO PLENO (SIN CORRELATO LEXEMÁTICO): TIPO (A)}

Llamamos así a los verbos que carecen de correspondencia lexemática y cuyo incremento pronominal reflexivo ${ }^{1}$ es obligatorio tanto semántica como sintácticamente: el /se/ y el resto del paradigma pronominal son morfemas desfuncionalizados $^{2}$ que, unidos al lexema del verbo, constituyen una sola base

1 Defendemos el carácter pronominal de estos verbos en tanto que su incremento forma parte del paradigma /me, te, se.../ -frente al /se/ unipersonal o pasivo-, si bien esta partícula afijal no tiene función, y es, por ende, componente o morfema de verbos pronominales. Hay otro modo de considerar el estatus y la función de se. En efecto, Amaya Mendikoetxea no distingue en su análisis, por ejemplo, entre un /se/ pronombre reflexivo y un /se/ afijo unipersonal o pasivo: «El estatus de se es el mismo en todas las construcciones: afijo verbal; su función varía dependiendo de si es parte de la conjugación objetiva (reflexivas, incoativas, pasivas con se, etc.) o de la conjugación subjetiva (impersonales con se)», vid. Amaya Mendikoetxea, «Construcciones con $s e$ : medias, pasivas e impersonales», en Ignacio Bosque y Violeta Demonte (dirs.), Gramática descriptiva de la lengua española, Madrid, Espasa-Calpe, 1999, vol. II, pág. 1652. Es decir, la función de se puede indicar bien que el sujeto gramatical se corresponde con el objeto nocional del verbo, bien que el objeto nocional coincide con el objeto gramatical.

${ }^{2}$ El entorno funcional de un verbo puede verse modificado al incrementarse pronominalmente: jactar el linaje / jactarse del linaje. Este hecho ha provocado la consideración del formante léxico —o componente morfemático— como índice de implicaciones funcionales — véase Carlos 
morfo-funcional. La referencia personal del paradigma me / te / se... está subordinada al sujeto gramatical del núcleo predicativo: la primera persona 'sujeto' exige /me/; la segunda, /te/, como quejarse, jactarse, enterarse, atreverse, arrepentirse $^{3}$, etc. En cuanto a su procedencia, se ha señalado para estos verbos pronominales un doble origen: sincrónico y diacrónico ${ }^{4}$.

El análisis sincrónico vendría dado por derivaciones parasintéticas a partir de otras unidades léxicas (sustantivos, adjetivos y verbos): 'afijo + lexema verbal + partícula pronominal / formante reflejo', como en emperrarse, desbandarse, resentirse, agarbarse, apropincuarse, apersonarse, etc ${ }^{5}$. Si la procedencia histórica consiste en anular la forma sintáctica oblicua — si ésta existe—, la base sincrónica tiene su razón de ser en la parasíntesis morfológica. De hecho, han interactuado entre sí, desde un principio, un origen sincrónico-morfológico y un origen diacrónico-sintáctico ${ }^{6}$. La confluencia entre sincronía y diacronía deriva: a) de la asunción de la parasíntesis por la fuente histórica, y b) de la observancia, desde la sincronía, de ciertos principios sintácticos asociados en su origen a la idiosincrasia del verbo pronominal, como pueden ser su imposibilidad de construirse con implementación y su necesidad de suplemento ${ }^{7}$.

Andrés Bello sugiere que, históricamente, muchos de los verbos pronominales fueron en un principio activos ${ }^{8}$ : «Así atreverse, que en el día de hoy no se emplea sino como verbo reflejo, se usó hasta el siglo XVII como verdaderamente activo, significando alzar, levantar, y, por una fácil transición, animar,

Hernández Sacristán, «En torno a los verbos pronominales y su doble origen», Lingüística Española Actual, VIII/1, 1986, pág. 60-. En efecto, en admirar algo / admirarse de algo, la partícula refleja provoca una reestructuración funcional sintáctico-semántica. Sin embargo, como el mismo Hernández Sacristán reconoce, aun aceptando dicha precisión de índice, no puede negarse el estatus morfemático del incremento reflejo y su carácter desfuncionalizado, al ser necesario para la construcción y significación precisa del verbo pronominal.

${ }^{3}$ Cuando aparecen delimitados por medio de adyacentes, «ninguno de los verbos llamados pronominales adopta el implemento, sino lo que llamamos suplemento: la pecadora se arrepintió $\rightarrow$ la pecadora se arrepintió de su vida pasada», según palabras de Emilio Alarcos en su Gramática de la Lengua Española, Madrid, Espasa Calpe, 1994, pág. 160.

${ }^{4}$ Hernández Sacristán propone "una fase histórica en la que contrastan forma refleja y oblicua a la que siguen una segunda fase en que se observa especialización semántica y construccional del verbo reflejo, y una tercera donde se da una caída en desuso de la forma no refleja» (art. cit., pág. 67).

${ }^{5}$ Podría ocurrir que sincrónicamente fuese la forma pronominal reflexiva la que actuase de embrión de construcciones no reflejas formadas en el nivel del discurso hablado. Así, de amancebarse *amancebar, de aborregarse *aborregar, de desternillarse *desternillar, etc.

${ }^{6}$ Hernández Sacristán, art. cit., pág. 71.

${ }^{7}$ No obstante, distinguimos un tipo de verbo pronominal capaz de regir acusativo: Tipo (B3).

${ }^{8}$ Andrés Bello [1847], Gramática de la lengua castellana destinada al uso de los americanos, Madrid, Arco/Libros, 1988. En el punto 762 de su Gramática, Bello señala que verbos reflejos, en un principio activos, admitían, antes de limitarse a la «construcción cuasi-refleja», toda clase de acusativos. Así, jactar (IACTARE + 'acusativo oblicuo'): Que no jacto valor de mis pasados (Ruiz de Alarcón). 
alentar, dar valor u osadía» ${ }^{9}$. Si aceptamos para este verbo la forma etimoló-

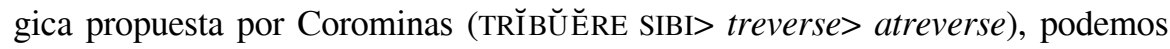
hablar, desde la diacronía, de una construcción parasintética sincrónica; vale decir: a un lexema verbal se le suma un componente protético y antes un derivado morfemático o formante reflejo.

\section{VERBOS PRONOMINALES EN GRADO RELATIVO (CON CORRELATO LEXEMÁ- TICO): TIPO (B)}

Llamamos así a los verbos pronominales con lexema coincidente con otros no pronominales y cuya incrementación morfemática se caracteriza por ser discrecional. A partir de este principio, podemos subdividir este tipo B en tres subgrupos: (B1): Verbos pronominales con morfema aspectual: usos intransitivos inergativos (verbos de 'movimiento', 'acción', etc.); usos inacusativos con se en oraciones incoativas (objeto nocional $\rightarrow$ sujeto gramatical) con sujeto +/- animado; oraciones medias-pasivas con /se/, etc.; (B2): Verbos pronominales con morfema de distinción léxica suplementativos (la implementación es imposible); y (B3): acusativos (permiten la implementación).

Existen, por otra parte, verbos que pueden constituirse como no pronominales, pronominales o doblemente pronominales ${ }^{10}$, como olvidar: Quise olvidarme de todo, y Se me olvidó que te olvidaba, a mí, que nada se me olvida.

(B1) El primer subgrupo queda para las «parejas» cuya diferenciación semántica es gradual y se establece generalmente por oposición sémica. La fun-

${ }^{9}$ Rufino José Cuervo [1874], Notas a la Gramática de la lengua castellana de don Andrés Bello, edición, variantes y estudio preliminar de Ignacio Ahumada Lara, Bogotá, Instituto Caro y Cuervo, 1981, pág. 251. Cuervo, en su Nota 101 a la Gramática de Bello, disiente al respecto: la forma atrever aparece a fines del siglo XVI y comienzos del siglo XVII por la «analogía de los verbos comunes que admiten la construcción refleja, como si se arguyera así: moverse presupone mover, luego atreverse, atrever» (pág. 252). Esta postura la consolida en su Diccionario de construcción y régimen (continuado por el Instituto Caro y Cuervo, Santa Fe de Bogotá, Instituto Caro y Cuervo, 1994). En el artículo atrever informa de que «el uso primitivo es el refl.; sólo por extensión analógica se llegó a emplear como simple verbo transitivo en la exuberancia sintáctica de los siglos XVI y XVII». En lo referente a la etimología propone como étimo el verbo del alto alemán medio strëben, «hoy streben, esforzarse», de donde el fr. estriver que recuerda a estreverse. «La combinación osar atreverse $=$ oser estriver merece particular atención, porque es indudable que en ella osar se toma sujetivamente y atreverse objetivamente, cosa que no sería de esperarse si atreverse representase a attribuere sibi». Radicalmente opuesta es la interpretación etimológica de Corominas en su Diccionario crítico, etimológico, castellano e hispánico, I-VI, Madrid, Gredos, 1980-1991, s.v., «del antiguo treverse 'confiar (en algo)', atreverse, y éste del lat. TRIBŬĔRE SIBI 'atribuirse (la capacidad de hacer algo)' [...] Nótese que treverse era primitivamente transitivo: "moros...en la su vezindat (de Mio Cid) non se treven ganar tanto" [...] de la idea de "atribuirse una capacidad' se pasó a 'confiar (en sí mismo)' [...] y de aquí 'atreverse'».

10 Leonardo Gómez Torrego, Valores gramaticales de «SE», Madrid, Arco/Libros, 1998, págs. 26-27. 
ción del elemento morfemático es la de modificar las características aspectuales del lexema del verbo ${ }^{11}$. Incluimos aquí tanto los usos intransitivos a priori o inergativos (morirse, salirse, estarse...), como algunos de los verbos inacusativos con se (formas o variantes intransitivizadas de verbos causativos o usos transitivos): verbos pronominales de 'sentimiento' (alegrarse, enamorarse, sonrojarse...), de 'mentalización' (despreocuparse, convencerse, asegurarse...), de 'arranque' o 'movimiento' (alejarse, apartarse, separarse...), de 'simetría' (adaptarse, acomodarse, adecuarse...), etc.

Verbos intransitivos (inergativos o inacusativos) como quedarse, entrarse, salirse, arrojarse, sentarse, etc., han resultado especialmente atractivos para la polémica y la discusión gramatical. Ya Bello en el punto 763 de su Gramática consideraba que «el pronombre reflejo está en acusativo, pero la reflexividad no pasa de los elementos gramaticales y no se presenta al espíritu sino de un modo sumamente fugaz y oscuro», punto éste que provocará la Nota 102 de Cuervo ${ }^{12}$. Para la distinción entre el sujeto agente y factitivo de los verbos sin partícula agregada y el sujeto experimentador de muchos verbos pronominales, es especialmente interesante el siguiente punto gramatical de Bello: «Bien es verdad que si fijamos la consideración en la variedad de significados que suele dar a los verbos neutros el caso complementario reflejo, percibiremos cierto color de acción que el sujeto parece ejercer en sí mismo. Estarse es permanecer voluntariamente en cierta situación o estado [...]. Entrarse añade a entrar la idea de cierto conato o fuerza con que se vence algún estorbo [...]. Lo mismo salirse [...]. Morirse no es morir, sino acercarse a la muerte. Nacerse es nacer espontáneamente $[\ldots] \gg^{13}$. Dentro de las construcciones pronominales aspectua-

${ }^{11}$ La oposición aspectual aristotélica en relación con los predicados lingüísticos fue retomada en la tradición gramatical hispánica por Andrés Bello, al distinguir entre verbos desinentes (delimitados o perfectivos) y verbos permanentes (no delimitados o imperfectivos). Hay que tener en cuenta que verbos delimitados aspectualmente por su significación precisa como perder pueden convertirse en no acabados desde un punto de vista sintáctico en oraciones como: El Madrid perdía el partido hasta que empató; o viceversa, una forma verbal no delimitada como vivir puede delimitarse en oraciones como: Juan vivió hasta los noventa años. Conviene, pues, diferenciar la forma aspectual flexiva de la del aspecto léxico-sintáctico.

12 Considera Cuervo en esta nota que «es ocioso discutir si es acusativo o dativo» un pronombre que actúa como «mero signo de espontaneidad»; así en verbos como irse, salirse, estar$s e$, etc., formados probablemente por analogía a partir de usos transitivos intransitivados con se, y que significan «movimiento o actitud espontánea», como moverse, ponerse, arrojarse, sentar$s e$, etc. Alarcos también considera que carece de sentido discutir la función tanto de los signos pronominales reflexivos cuando éstos son obligatorios y simple repercusión de la persona del sujeto gramatical (arrepentirse, quejarse...), como del «incremento personal» que acompaña reflexivamente a verbos como dormirse, irse... (Alarcos, op. cit., págs. 159-161).

${ }^{13}$ Cuervo, op. cit., pág. 256. La nota 103 de Cuervo a la Gramática de Bello dice así: «Morirse, además de significar acercarse a la muerte, denota la muerte natural a diferencia de la violenta; así no puede decirse que alguien se murió fusilado, pero sí que se murió de tisis o pulmonía». En este sentido, es interesante ver cómo la semántica contextual puede favorecer la 
les incoativas con sujetos afectados, tenemos que distinguir las que expresan un cambio de estado físico o psíquico que un sujeto gramatical /+ animado/ padece o experimenta, ya sean ingresivas (marearse, sentarse...), progresivas (adormecerse, preocuparse...) o resultativas (curarse, despertarse...), y cuya forma verbal simple se caracteriza, en contraposición, por llevar un sujeto agente y un significado factitivo ${ }^{14}$, tenemos que distinguirlas, decimos, de las consideradas por Amaya Mendikoetxea oraciones incoativas medias. Estas últimas se diferencian de las anteriores por construirse con un sujeto gramatical /-animado/: El bosque se quemó, El jarrón se cayó ${ }^{15}$. Consideramos éstas y las construcciones verbales con la unidad lingüística /se/ de las llamadas oraciones medias-pasivas ${ }^{16}$ como voz media del español.

desambiguación sintáctica de la oración. Una oración como Se envenenó puede ser interpretada como activa impersonalizada (Se produjeron envenenamientos), reflexiva (Se envenenó a sí mismo), construcción pasiva (Fue envenenado) y construcción intransitiva inacusativa (Se envenenó comiendo setas en mal estado). Otras teorías apuestan por la naturaleza expletiva de se en tales casos. Así, se ha hablado de un se reforzador de intransitividad enfático (Álvarez Martínez), de un SN3 expletivo (H. Alonso), de un «locativo mínimo o implícito idéntico al Agentivo o al Experimentador», según Martín Zorraquino en su excepcional trabajo Las construcciones pronominales en español. Paradigma y desviaciones, Madrid, Gredos, 1979, pág. 113, etc. Pensamos que verbos como morir y morirse no son equivalentes, ya que responden a un origen externo y un proceso interno respectivamente. Para este aspecto, vid. R. Trujillo, Introducción a la semántica española, Madrid, Arco/Libros, 1988.

${ }^{14}$ En estos verbos pronominales de aspectualidad distintiva, el sujeto léxico recibe experimentalmente la predicación del núcleo verbal. De ahí que a la oposición 'forma pronominal / no pronominal' corresponda, a un mismo nivel, la oposición 'sujeto experimentador / sujeto agente'. Así, en a) Juan emborracha a su amigo y b) Juan se emborracha con su amigo, se enfrentan un sujeto agente y otro experimentador, la presencia y ausencia de implementación y un significado factitivo frente a otro no factitivo. Asimismo, en a) Juan duerme y b) Juan se duerme, se distinguen los parámetros aspectuales de 'duratividad' y 'no delimitación' frente al parámetro de 'incoatividad' ingresiva o inceptiva. En este sentido, se ha considerado que, puesto que en la lengua existe un verbo dormir y un verbo dormirse, éstos y otros semejantes «deberían aparecer como entradas diferentes» en los diccionarios (Gómez Torrego, op. cit., pág. 24).

15 Dentro del marco global de oraciones medias en sentido amplio, incluye Amaya Mendikoetxea (en I. Bosque y V. Demonte (dirs.), op. cit., vol. II, págs. 1639- 1642) las oraciones pronominales con sujetos afectados con posibilidad de inclusión del paradigma /me, te, se.../: oraciones reflexivas: El niño se lava, pseudo-reflexivas: El muchacho se desmayó e incoativas: El perro se asustó; y las oraciones medias con se (con morfema obligatorio /se/ y un sujeto nocional implícito) que incluyen, por un lado, las oraciones pasivas: Este libro se vende en todas las esquinas, y las impersonales: Se asustó a los niños, y por otro, las subclases medias-pasivas: Este libro se vende muy bien, y las medias impersonales: A estos niños se les asustó fácilmente. Fuera de este cuadro y, por lo tanto, no consideradas oraciones medias, quedan las oraciones con dativo ético: Este niño me come muy bien, las que hemos considerado asociadas a un significado aspectual: El niño se durmió y las construcciones con verbos de movimiento como marcharse, venirse, irse, etc.

${ }^{16}$ Estas oraciones, subclase de las pasivas con $s e$, están caracterizadas por ser proposiciones estativas con sujeto no animado, de aspecto genérico y necesitantes de algún modificador adverbial: Esta camisa se lava muy bien con lejía, Las luces reflectantes se ven fácilmente, Los trabajos escritos a máquina se leen más deprisa, etc. 
(B2) En este segundo subgrupo incluimos los verbos privilegiados por una doble posibilidad de construcción morfemática (al construirse o no con partícula afijal), pero cuyos significados devienen de una oposición más privativa que gradual: acordar / acordarse, ocupar / ocuparse ${ }^{17}$, creer / creerse, gloriar / gloriarse, postrar / postrarse, esfumar / esfumarse, enrollar / enrollarse, chiflar /chiflarse, ordenar / ordenarse, engreír / engreírse, etc. Todos estos verbos, una vez incrementados con la partícula-morfema, modifican el contenido léxico del verbo no pronominal, resultando verbos distintos significativamente (y no sólo distinguidos por parámetros aspectuales). En este subgrupo, como en (A), la función de suplemento (complemento regido, vale decir) se halla presente al menos de una manera implícita, pues, como pensaba Alarcos, «habiendo incremento reflexivo obligatorio el implemento es imposible» ${ }^{18}$. En efecto, es éste un principio sintáctico cumplido en los verbos de este subgrupo B2. Ahora bien, ¿qué ocurre cuando, una vez incrementada una forma verbal causativa con la partícula del paradigma /me, te, se.../, el resultado no responde a un uso inergativo ni inacusativo de un verbo pronominal, sino que, por el contrario, exige un implemento?

$\mathrm{Si}$, a partir de la adición de una partícula sin función nominal a una forma verbal simple, el sentido de un verbo puede aparecer modificado, podemos preguntarnos hasta qué punto sería lícito excluir de una tipología de verbos pronominales a aquellos verbos capaces de regir acusativo. Incluimos este tipo en (B3).

(B3) Este tercer subgrupo supone la construcción formada con verbo pronominal + implemento. No han faltado propuestas de definición para esta subclase. La que más se aproxima a la nuestra es la denominación de verbos semilocucionales o semipronominales ${ }^{19}$. Si bien, debido a su especial combinación sintáctica, se integran en este estrecho marco, sobre todo, verbos pronominales componentes del discurso repetido (expresiones locucionales categorizables ${ }^{20}$, paremias, etc.) o bien verbos pronominales participantes de una

${ }^{17}$ Cuervo observó en la Muestra cómo la forma ocuparse en se sustituye por la expresión, tomada del francés, ocuparse de, lo que el lexicógrafo consideraba «inadmisible».

18 Alarcos, op. cit., pág. 160.

${ }^{19}$ Gómez Torrego, op. cit., pág. 16.

${ }^{20}$ Extraídas a partir del verbo simple (a) ganar las locuciones significantes (b) ganarse a pulso (algo) 'Conseguir o merecer [alguno] por propios méritos o deméritos [alguna cosa]', (c) ganarse la vida 'Solventar [alguien] su modo de vida [haciendo algo o con algo]', y (d) ganársela 'Recibir [alguno] una bronca o castigo [por algo mal hecho, reprobatorio]', pueden construirse las siguientes expresiones:

(a) Juan ganó el partido // Juan lo ganó

(b) Juan se ha ganado a pulso su mala reputación // Juan se la ha ganado a pulso

(c) Juan se gana la vida haciendo chapuzas // *Juan se la gana haciendo chapuzas

(d) Juan se la ganó cuando rompió el florero a su madre //*Juan se ganó cuando... 
expresión de sentido figurado: ganarse / jugarse la vida, llevarse el gato al agua, chuparse el dedo, apretarse el cinturón, hacerse el sueco, morderse la lengua, sujetarse los machos, saltarse a la torera [algo], perderse (lo), arreglarse (las), apañarse (las), etc. Un caso especial puede ser el verbo figurarse en Él se figura que todo se olvida / que la casa es blanca, etc., (frente a la forma no pronominal de Él figura una comedia, Él figura empadronado...).

Vamos a ocuparnos ahora de las transposiciones semánticas de algunas locuciones significantes verbales (las que tienen como núcleo un verbo pronominal) tomando como base la Muestra lexicográfica de V. G. Manrique y Rufino J. Cuervo.

\section{LA PRONOMINALIZACIÓN EN EL DISCURSO REPETIDO}

La Muestra de un diccionario de la lengua castellana (1871) recoge en la entrada ojo una considerable compilación de expresiones fraseológicas, cuyos valores semánticos y pragmáticos varían en función del comportamiento sintáctico-funcional, orden e integración de sus distintos componentes lingüís-

Por un lado, (a) y (b) muestran que ganarse es un verbo pronominal en grado relativo y que puede aparecer con un término adyacente en función de implemento («su mala reputación»), así es posible llenar la casilla vacía de OD de la locución con un referente pronominal: Juan se la ha ganado a pulso. En cambio, si sustituimos en (c) el sintagma que en la técnica del discurso libre cumpliría una función implementiva («la vida»), el resultado es una locución significante verbal distinta, pues tiene entonces el mismo sentido que presenta (d), cuya construcción ha de ser a la fuerza doblemente pronominal (ganársela), como ocurre con Írsele a uno los ojos por o tras [alguna persona o cosa], Conocérsele [a uno alguna cosa] en lo blanco del ojo, o Alegrársele a uno los ojos. Por otra parte, al definir el significado idiomático de estas expresiones, comprobamos cómo los componentes del régimen lexemático, si bien informan sobre los usos contextuales sintácticos y semánticos del definido, no deben ser incluidos al operar con el principio lexicográfico de sustitución. Así, Juan ha conseguido / ha merecido por propios deméritos su mala reputación, Juan solventa su modo de vida haciendo chapuzas, Juan recibió un castigo cuando rompió el florero a su madre. Al ser categorizables, estas locuciones — significantes verbales - funcionan en el enunciado oracional como verbos monolexémicos. Es el contorno de la definición el índice que marca la posibilidad o imposibilidad de implementación; así, viene a coincidir desde un nivel sintáctico-semántico-pragmático con la casilla vacía de ganarse a pulso [algo]. En cambio, en ganarse la vida sólo es posible admitir la función acusativa si tomamos el enunciado como técnica del discurso y no como discurso repetido, pues no es posible -dado que desaparece la determinación de su contenido locucional- la expresión *Juan se la gana haciendo chapuzas. Sí sería gramaticalmente correcto y semánticamente aceptable el proceso contrario, es decir, el proceso que va del referente pronominal a un sintagma en función de implemento: de ganársela podemos inferir un enunciado como Juan se ganó una bronca. No obstante, si atendemos a los valores pragmáticos que conlleva toda locución, tenemos que distinguir por sus implicaciones especiales a ganarse [una bronca] de ganársela. Esto demuestra, de alguna forma, que los componentes locucionales cumplen, dentro del marco oracional, una sola función sintáctica (además de semántica y pragmática) que equivale a la que cumpliría en el mismo marco oracional y discursivo una categoría gramatical, y que, por tanto, no es posible desglosar de una expresión pluriverbal fija más de un valor funcional a partir de sus distintos componentes. 
ticos $^{21}$. Sólo contemplamos aquí las locuciones significantes verbales ${ }^{22}$ cuyo núcleo se corresponde con un verbo pronominal (tenga éste o no correspondencia lexemática no pronominalizada):

\section{a) Locuciones significantes verbales con núcleo predicativo pronominal:}

- Encarnizarse los ojos. Encenderse, inflamarse en ira.

- Taparse de medio ojo. Se decía de las mujeres cuando se tapaban la cara con la mantilla sin descubrir más que un ojo, para ver sin ser conocidas.

- Vendarse los ojos. No querer asentir ni sujetarse a la razón, por clara que sea.

- Venirse a los ojos. Saltar a los ojos.

- Vidriarse los ojos. Tomar estos la apariencia o semejanza del vidrio, como sucede a los moribundos ${ }^{23}$.

(i) Locuciones con variabilidad sinonímica en el componente nuclear:

- Quitarse o hurtarse de los ojos. Sustraerse de las miradas (de alguno) ${ }^{24}$.

- Llenarse, henchirse o rasarse los ojos de agua. Arrasarse los ojos en lágrimas.

${ }^{21}$ Es muy frecuente que sea el verbo pronominal el componente invariable en locuciones significantes verbales como en Irse al traste, por las ramas, a pique, al cuerno, de la lengua, de este mundo, al otro barrio, a la acera de enfrente, de picos pardos, por los cerros de Úbeda, con viento fresco, a la porra, al garete, írsele a uno la cabeza, el santo al cielo, etc.

${ }^{22}$ Para la tipificación locucional por categorías léxico-gramaticales (significantes o conexivas), vid. Julio Casares, Introducción a la lexicografía moderna., Madrid, CSIC, 1950.

${ }^{23}$ Cuando la transposición semántica afecta sólo a uno de los componentes locucionales y existe coincidencia entre algún sema del significado literal y del significado idiomático, como ocurre en despabilarse / encarnizarse / vidriarse los ojos, el grado de lexicalización de estas unidades se acerca al que Weinreich otorgaba para las llamadas «unidades fraseológicas», a juicio de J. Á. Porto Dapena, Manual de técnica lexicográfica, Madrid, Arco/Libros, 2002, pág. 152. L. Ruiz Gurillo se refiere a expresiones como darse un baño como «unidades sintagmáticas verbales», vid. La fraseología del español coloquial, Barcelona, Ariel, 1998, págs. 38-44. Gloria Corpas hablaría de colocaciones (esfera I) en unidades fraseológicas como declararse un incendio, frente a las locuciones (esfera II) o los enunciados fraseológicos (esfera III), como defiende en su Manual de fraseología española, Madrid, Gredos, 1996, págs. 50-52.

${ }^{24}$ R. J. Cuervo, en sus «Observaciones sobre el Diccionario de la Real Academia Española (Undécima edición año de 1869)» (1874), señala la importancia y conveniencia de indicar formalmente (entre paréntesis cuadrados) el régimen o contorno de la definición. Como vemos, lo lleva a la práctica en la Muestra y lo hará, más tarde, en su Diccionario de construcción y régimen (1886-1893). Hoy es algo común y obligado en la práctica lexicográfica. Para el concepto de «contorno», vid. I. Ahumada Lara, «Contorno de la definición verbal y régimen lexemático: su indicación formal en la lexicografía hispánica», en Amistad a lo largo. Estudios en memoria de J. Fernández-Sevilla y N. Marín López, Granada, Servicio de Publicaciones de la Universidad, 1987, págs. 13-25; y M. Seco, «El 'contorno' en la definición», en Estudios de lexicografía española, Madrid, Paraninfo, 1987, págs. 35-45. 
b) Locuciones significantes verbales con verbo pronominal en grado relativo:

(i) El nuevo morfema o componente no afecta al significado global de la expresión conjunta (nueva forma de variabilidad sinonímica):

- Despabilar o despabilarse los ojos. Abrirlos.

- Llevar o llevarse los ojos. Llamar o atraer la atención.

- Hacer, hacerse del ojo. Hacer, hacerse señas guiñando el ojo para dar a entender algo sin que se note ${ }^{25}$.

(ii) El nuevo morfema provoca una traslación del significado idiomático:

- Sacar los ojos. Apretar, urgir (a alguno).

- Sacarse los ojos. Reñir o alterar con enojos y cólera.

- Quebrar los ojos ${ }^{26}$. Desplacer o desagradar (a alguno) en aquellas cosas que son de su gusto; afligir, desazonar.

- Quebrarse los ojos. Cansarse estos por la mucha fatiga que se toma en alguna cosa, como en leer, etc. ${ }^{27}$

- Hacer ojo. Estar (el peso) poco equilibrado y cargar más a la una balanza que a la otra.

- Hacerse ojos. Estar muy solícito y atento (para conseguir o ejecutar alguna cosa que se desea o para verla y examinarla).

${ }^{25}$ Para dar a entender algo sin que se note puede considerarse información sobre la posibilidad del uso comunicativo, y, por lo mismo, podría señalarse a través de una marca pragmática. María Moliner se ocupa de dicha información en su Diccionario de uso del español (Madrid, Gredos, 1966). Las marcas de pragmática aparecen señaladas sistemáticamente en el ámbito de la lexicografía española en el Diccionario Salamanca de la lengua española (Madrid, Santillana, 1996).

${ }^{26}$ La locución Quebrar los ojos puede entenderse como significante nominal infinitiva (no conjugable en forma personal) o como significante verbal conjugable: Juan (te, le,...) quebró los ojos. La casilla vacía no forma parte de la locución. Señala Porto Dapena (op. cit., pág. 155) que, cuando las locuciones presentan variabilidad con casilla vacía, es impropio hablar, como hace J. Martínez Marín en Estudios de fraseología española, Málaga, Ed. Librería Ágora, 1996, págs. 56-57, de «contorno». En efecto, éste es un término reservado en lexicografía para señalar componentes anexos a la definición propiamente dicha. No obstante, esta casilla vacía viene a coincidir con el régimen lexemático de la definición. Así es posible proyectar la función sintáctico-semántica (incluso pragmática) indicada por el contorno en el núcleo predicativo locucional: Quebrar los ojos (a alguno). Desplacer o desagradar (a alguno). En cambio, en una locución como Quebrar los ojos al diablo esa casilla vacía ya no es tal, sino un sintagma prepositivo fijo (sin función sintáctica en el discurso repetido, mas no sin valores pragmáticos y semánticos): «al diablo». Si existen grados de idiomaticidad (total — sacarse los ojos-, parcial —Quebrarse los ojos-, indirecta — Quitarse de los ojos — o nula —Llenarse los ojos de lágrimas-), el principio de fijación fraseológica puede admitir distintas posibilidades de estabilidad, siempre que se mantengan medio estables el sentido y la carga expresiva o pragmática. Puede ser posible la variabilidad sinonímica si ésta es plena (Quebrar el ojo al demonio) o creativa (Quebrar el ojo al malo). Joseph. V. Ricapito y Shalom Lindebaum asocian la frase quebrar el ojo 'cegar' al hebreo en su artículo «Quebrar el ojo: posibles orígenes de su significado en hebreo», RFE, LXXVII, 3-4, 1997, págs. 321-327.

${ }^{27}$ Los límites pragmáticos, semánticos y sintácticos interactúan en este tipo de «fórmula» definicional. 
Desde el aspecto formal, estas unidades polilexémicas atienden, pues, a una doble estructuración compositiva ${ }^{28}$ :

a) Verbo pronominal + Sintagma nominal: Hacerse ojos (frente a Hacer ojo).

b) Verbo pronominal + Sintagma prepositivo: Hacerse del ojo (y Hacer del ojo).

En (a) el entorno actancial del verbo sin incrementación morfemática reforma (con el núcleo pronominalizado) sus valencias exigidas ${ }^{29}$. En (b) el entorno actancial no se modifica aparentemente con dicha incrementación, sí, por el contrario, el entorno funcional: los verbos pronominales en grado relativo, sobre todo del tipo (B2), van a construirse con un suplemento en lugar del implemento exigido por el verbo simple. Sin embargo, este suplemento, al encuadrarse como formante idiomático en una locución verbal, se desfuncionaliza, por lo que también aquí nos encontramos con una reestructuración que conlleva la pérdida de un actante. En resumidas cuentas, en una locución significante verbal, el núcleo predicativo puede ser el componente que dicte, a través de su flexión morfemática (presencia o ausencia de partícula pronominal), el contenido léxico-semántico del discurso repetido. Así en Quebrar / Quebrarse los ojos. Por otra parte, la unidad verbal lexemática es insustituible sinonímicamente y se considera invariante en casos como Quebrarse / Quebrantarse los ojos ('fatigarse' y 'turbarse la vista' respectivamente). Los sintagmas adyacentes pueden, al mismo tiempo, marcar diferencias distintivas entre locuciones con idéntico lexema nuclear, así en Quebrar el ojo / los ojos al diablo frente a Quebrar los ojos. Sin olvidar, por último, que toda unidad idiomática supone, en distinto grado, una traslación (metafórica, metonímica, etc.) total o sémica del significado literal.

${ }^{28}$ Esta doble estructuración presupone que el componente sintagmático pueda estar matizado por adyacentes que formen parte invariable de la locución idiomática, como en Meterse por el ojo de una aguja (frente a Meter / Meterse (le) por los ojos (alguna cosa), o la «frase» Quebrar un ojo al diablo 'Hacer estrena en algo'. Vid. G. Correas, Vocabulario de refranes, Madrid, Visor Libros, 1992, pág. 635.

${ }^{29}$ El sintagma nominal de Hacer ojo / Hacerse ojos que se corresponde funcionalmente con el objeto directo que exige el verbo, considerado éste como parte nuclear de la técnica del discurso libre, pasa a convertirse, en el discurso repetido, en un componente o formante fraseológico sin función. Y es que la unidad locucional, tomada en conjunto, ejerce la misma función que una lexía en el plano sintagmático de la oración, y es sustituible paradigmáticamente por otras unidades simples del sistema lingüístico al que pertenece. La fraseologización de una locución significante implica, pues, transformar un sintagma o discurso libre en una unidad idiomática fijada y categorizable gramaticalmente: Quebrar / Quebrarse los ojos, Hacerse ojos, etc., son locuciones verbales intransitivas. La casilla vacía de Quebrar los ojos (a alguno) no forma parte del contenido locucional, aunque la expresión idiomática exija su presencia funcional. Si esta función exigida por el discurso repetido es la de OI, el verbo no pronominal pierde entonces un actante, el argumento con función OD, es decir, la locución significante verbal sigue siendo de suyo intransitiva en estos casos. 